\title{
Placentitis bacteriana como causa de aborto en yeguas: reporte de caso
}

\author{
Placentitis Bacterial as a cause of abortion in mares: Case Report
}

\section{Placentite causa bacteriana de aborto em éguas: relato de caso}

\author{
Jennyfer Ruiz-Jiménez ${ }^{1}$, Jair Perez-Osório² ${ }^{2}$ José A. Espinosa-S ${ }^{3}$, Andrés $F$. Valencia- $H^{4}$, \\ Dumar A. Jaramillo-Hernández ${ }^{5}$
}

1 MV, Facultad de Ciencias Agropecuarias, Universidad de La Salle, Bogotá, Colombia.

2 MVZ, MSc, PhD, Universidad de La Salle (Bogotá). Facultad de Ciencias Agropecuarias. Programa de Medicina Veterinaria, Programa de Posgrados Maestría y Doctorado en Agrociencias, Profesor Titular, área Reproducción y Biotecnologías.

3 MV, MSc, Universidad de la Salle (Bogotá), Facultad de Ciencias Agropecuarias, Docente de Catedra del Programa de Pregrado y Posgrados en las áreas de Clínica y Medicina de equinos.

4 MV, MSc, Universidad de la Amazonia (Florencia - Caquetá). Facultad de Ciencias Agropecuarias. Programa de Medicina Veterinaria y Zootecnia. Profesor área de Clínica de Grandes Animales.

5 MVZ, Esp, MSc, Universidad de los Llanos (Villavicencio -Meta), Facultad Ciencias Agropecuarias y Recursos Naturales. Escuela de Ciencias Animales. Profesor Clínica de grandes animales.

Email: jairperez@unisalle.edu.co

Recibido: agosto 28 de 2017

Aceptado: septiembre 24 de 2018

\section{Resumen}

La placentitis en yeguas ocasionada por bacterias es una de las causas más importantes de abortos, en Colombia no existe evidencia escrita de su presentación. En el presente artículo se reporta el caso de una yegua Silla Francesa de 10 años de edad, que abortó a los 9 meses de gestación y fue atendida en la Clínica Veterinaria San Jorge - Escuela de Equitación Ejército Nacional en Bogotá. La paciente presentó signos de lactancia prematura y se observó engrosamiento de la placenta, además en los hallazgos histopatológicos predominan cambios vasculares (congestión, edema y fibrina) lo que indica una placentitis aguda. En la tinción de Gram de la placenta se encontraron cocobacilos gram negativos adheridos a la superficie de las células de las vellosidades corioalantóicas y entremezclados con el material proteináceo, aparentemente algunos se ubican intracelularmente; asociando estos fenómenos a un proceso infeccioso por posibles enterobacterias (E.coli o Salmonella spp).

Palabras claves: Aborto; enterobacterias; feto; placenta; yegua.

\begin{abstract}
Placentitis in mares caused by bacteria is one of the most important causes of abortions, there aren't any documented cases in Colombia as of yet. In this article, we take a look at a particular case of a "Silla Francesa" mare 10 years of age. The Mare had an abortion at 9 months of gestation and was treated at the Veterinary Clinic San Jorge - Army Equitation School from Bogota. The mare suffered from a premature lactation and presented thickening in the placenta which indica-
\end{abstract}


ted placentitis, showing signs of vascular changes (congestion, edema and fibrin).In gram staining of placenta, It was found a negative gram coccobacilli adhered to the surface of the chorioallantoic villus cells and mixed with the proteinaceous material, apparently some are located intracellularly, confirming the process of infection potentially due to the presence of enterobacteias. (E.coli or Salmonella sp).

Keywords: Abortion; enterobacteria; fetus; placenta; mare.

\section{Resumo}

O placentite em éguas causadas por bactérias é uma das mais importantes causas de abortos, na Colômbia não está escrita a apresentação de provas. Este artigo relata o caso de uma égua cadeira francesa de 10 anos de idade, que o aborto aos 9 meses de gestação e foi tratado na Clínica Veterinária São Jorge - Escola de Equitação do Exército em Bogotá. O paciente apresentou sinais de lactação prematura e espessamento foi observado indicando placentite placenta porque predominantemente alterações vasculares agudas (edema, congestão e fibrina). Na coloração de gram da placenta, cocobacilos gram-negativo foi encontrada aderida à superfície das células das vilosidades corioalantóicas e misturado com o material proteico, aparentemente algumas estão localizadas intracelularmente, o que confirma o processo de potencial infeccioso de enterobactérias (E. coli ou Salmonella sp).

Palavras chave: Aborto; enterobactérias; fetos; placenta; égua.

\section{Introducción}

La placentitis bacteriana es la inflamación de la placenta y puede ser causada por bacterias gram negativas y gram positivas; como bacterias gram positivas asociadas a esta patología se encuentran Streptococos $\beta$-hemolíticos (Streptococcus equi subspecies zooepidemicus y Streptococcus equisimilis), Staphylococcus spp, Corynebacterium pseudotuberculosis, Nocardia spp; y como bacterias gram negativas están Escherichia coli, Pseudomonas spp, Klebsiella spp, Salmonella abortus equi, Leptospira pomona (hematógena) (Hong et al., 1993; Pycock, 2009; Munroe y Weese, 2011); predominantemente en las placentitis ascendentes las bacterias Streptococos $\beta$-hemolíticos y Escherichia coli son las de mayor importancia clínica (Williams et al., 2004; Canisso et al., 2015).

Esta enfermedad cursa con descarga vulvar que puede ser mucoide progresando a purulenta y/o hemorrágica, desarrollo mamario con o sin lactancia precoz y relajación de la musculatura pélvica. Aunque a veces la descarga vulvar no siempre se encuentra presente o puede ser que la cantidad de exudado que elimina sea muy escaso y difícil visualizarlo (Pycock, 2009; Troedsson et al., 1997). La placenta puede presentarse sin alteraciones macroscópicas o estar edematizada con alteraciones en su coloración por la pérdida de vellosidades, se puede presentar una secreción mucopurulenta que drena hacia el exterior por el cérvix, así como también puede presentar diversas alteraciones que dependen del agente agresor actuante (Troedsson et al., 1997; Reed et al., 2005).

Existen tres rutas de infección genital que conducen a la presentación de la placentitis y posterior aborto: I. vía hematógena al feto debido a la infección uterina de la yegua, II. vía local debido a focos de infección instalados en la profundidad del endometrio y III. infecciones ascendentes vía cérvix que ocasionan placentitis. Las infecciones ascendentes son las causas más comunes que producen abortos en las yeguas.

El feto se infecta por la diseminación bacteriana a través del líquido alantoideo y el líquido amniótico hacia el estómago y los pulmones, como así también se puede infectar a través de las venas alantoideas. La preñez se mantiene hasta que la superficie remanente de la placenta funcional es insuficiente para mantener la función del feto, por lo que se produce la alteración o la muerte y posterior expulsión de éste. En forma alternativa se puede producir en primer término una septicemia que resulta en muerte fetal y aborto; por otra parte, el feto abortado puede encontrarse deshidratado y emaciado debido a la deficiencia placentaria progresiva. Las yeguas que pueden abortar como consecuencia de una placentitis ascendente deben ser sometidas a la operación de Caslisk luego del servicio; así mismo se debe tener en cuenta la utilización de la inseminación artificial cuando sea posible y emplear técnicas de servicios con la menor contaminación posible (Robinson, 1992; LeBlanc et al., 2004).

Por otra parte, en los hallazgos macroscópicos de placentas afectadas por esta patología se puede evidenciar el corion afectado cubierto por un exudado marrón y espeso producido por el desprendimiento de las microvellosidades y sangre; permitiendo visualizar una línea de demarcación entre la placentitis y el corion normal.

El diagnóstico imagenológico es importante, en el cual a través de la ultrasonografía se puede evidenciar en- 
grosamiento y edema del corioalantoides y el desprendimiento del corioalantoides-endometrio en el polo caudal placentario (Troedsson et al., 1997; Troedsson y Zent, 2004). Recientemente, en modelos experimentales de placentitis originados en la yegua se han identificado varios marcadores moleculares (amiloide sérico A, haptoglobina, $17 \beta$-estradiol y $\alpha$-fetoproteína) que pueden funcionar como pruebas de diagnóstico en placentitis espontánea, Wynn et al., (2016).

La placentitis bacteriana puede ocurrir en cualquier momento durante la gestación con dos presentaciones clínicas reportadas: aguda y crónica; la presentación aguda (y sus variantes: focal o difusa) se asocia a infiltración neutrofílica y necrosis de las vellosidades coriónicas; principalmente se produce a principios o mediados de la gestación; en la presentación crónica (y sus variantes: focal o extensa) las lesiones están centradas alrededor de la zona de la estrella cervical caracterizadas histopatológicamente por material eosinofílico en el corión, necrosis de las vellosidades, hiperplasia adenomatosa e infiltración de células mononucleares, Carleton (2011). Las infecciones ascendentes intrauterinas están asociadas con bacterias que migran desde la vagina infectando los tejidos cercanos al cérvix, estableciendo un foco inflamatorio primario. El huésped responde con procesos inflamatorios agudos, caracterizado en las primeras 48 horas con la producción de prostaglandinas (prostaglandina E2 y prostaglandina $\mathrm{F} 2 \alpha$ ); así mismo, citoquinas pro-inflamatorias (IL-6 e IL-8, principalmente) que favorecen la mayor producción de prostaglandinas por parte del amnios y corion (LeBlanc et al., 2004; Lyle, 2014), éstas pueden generar una hipermovilidad posterior que puede impedir el flujo de sangre de la placenta a medida de que se contrae, reduciendo la oxigenación que debe recibir el feto y favoreciendo su estrés, Reed et al., (2005). El objetivo del presente reporte es describir un caso de aborto asociado a placentitis aguda de origen infeccioso por posibles enterobacterias (E.coli, Salmonella sp) en una yegua de raza silla francesa de 10 años de la ciudad de Bogotá (Colombia).

\section{Descripción del caso}

En la Clínica Veterinaria San Jorge - Escuela de Equitación Ejército Nacional ubicada en la ciudad de Bogotá, ingresa una yegua de 10 años con un peso de $400 \mathrm{~kg}$ de la raza Silla Francesa con una gestación de 9 meses cuyo motivo de consulta la fue la presentación del inicio prematuro de la lactancia.

En el examen clínico se encontró: frecuencia cardiaca $42 \mathrm{l} / \mathrm{min}$, frecuencia respiratoria $22 \mathrm{r} / \mathrm{min}$, temperatura rectal de $38.1^{\circ} \mathrm{C}$, tiempo de llenado capilar 2 segundos y mucosas rosadas. En el sistema tegumentario se encontró aumento de tamaño de la glándula mamaria y producción de leche; signos de molestia abdominal leve y relinchos constantes. A la palpación transrectal se evidenció gestación de 220 días aproximadamente, feto activo y responsivo a estímulos de presión leve, al examen ultrasonográfico se encontró un engrosamiento de la estrella cervical (espesor $18 \mathrm{~mm}$ ). Tanto el sistema respiratorio, digestivo, nervioso, musculo esquelético y genitourinario se encontraron sin anormalidad aparente.

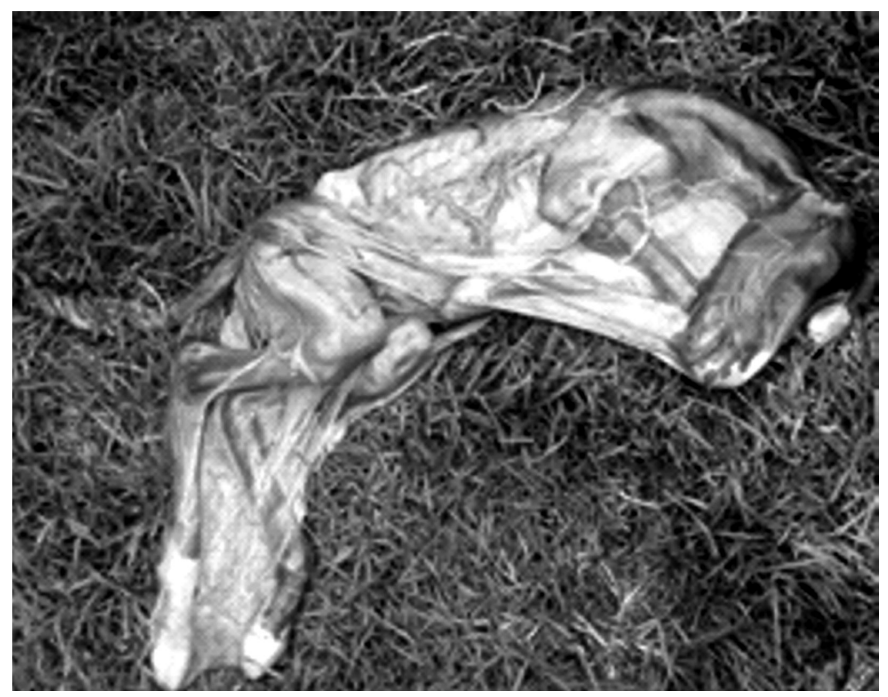

Figura 1. Potro de tamaño reducido con 9 meses de gestación con condición corporal 1.5/5, nótese el arco costal prominente. Fuente: elaboración propia. 
Fueron realizados exámenes paraclínicos de hemograma y prueba serológica MAT (prueba de aglutinación microscópica) para Leptospira sp. (ver tabla 1). Las variables medidas en el hemograma se encontraron entre los rangos normales para la especie y el examen serológico reportó resultado negativo a Leptospira sp. 18 horas posterior de la llegada del paciente se presenta el aborto (ver figura 1), sin la expulsión de la placenta. Se emitió como diagnóstico de trabajo: Aborto de probable origen infeccioso y retención de placenta.

Posterior a este hecho, la paciente fue medicada con $1.1 \mathrm{mg} / \mathrm{Kg}$ IV de Flunixin meglumine (Finadyne ${ }^{\circledR}$ ), Oxitocina 40 UI dosis dividida IM e IV, Fluidoterapia con solución de Lactato de Ringer (12 L IV), antibioticoterapia de amplio espectro (Dalipen $6 \circledR 20 \mathrm{~mL} I \mathrm{M}$ ) y ducha de agua fría en la ubre. 12 horas posterior a la implantación de la terapia farmacológica hubo exposición vulvar de la placenta, procediendo a administrar una segunda dosis de Oxitocina $1 \mathrm{UI} / \mathrm{min}$ IV CRI por 8 minutos, tiempo en el cual la placenta es expulsada por completo; sumado a la retracción mecánica de la placenta. La terapia antiinflamatoria fue mantenida por cinco días, la antibiótica por diez días, así como la fluidoterapia según requerimiento y también fue implementado un lavado uterino con solución de lactato de Ringer atemperada + solución de yodo $0.1 \%$.

Tanto la placenta como el feto fueron enviados al Laboratorio de Patología Veterinaria de la Universidad Nacional de Colombia para la realización de necropsia fetal y estudio histopatológico del tejido placentario y órganos fetales.

\section{Resultados}

\section{Hallazgos Anatomopatológicos:}

Placenta: Alantocorion, superficie externa de coloración café claro con áreas de coloración oscura y aspecto rugoso y sucio, al interior extensas áreas grises con aparente desvitalización tisular delimitadas en algunas regiones por zonas de aspecto hemorrágico y alrededor zonas extensas de moderado enrojecimiento difuso. Alantoamnios de aspecto edematoso y coloración rojiza generalizada (ver figura 2).

Potro: tamaño reducido para la edad de gestación reportada y con evidente subdesarrollo para la raza, tonsilas levemente aumentadas de tamaño y enrojecidas.

Los Hallazgos anatomopatológicos observados durante la necropsia fetal se resumen en la tabla 2. 

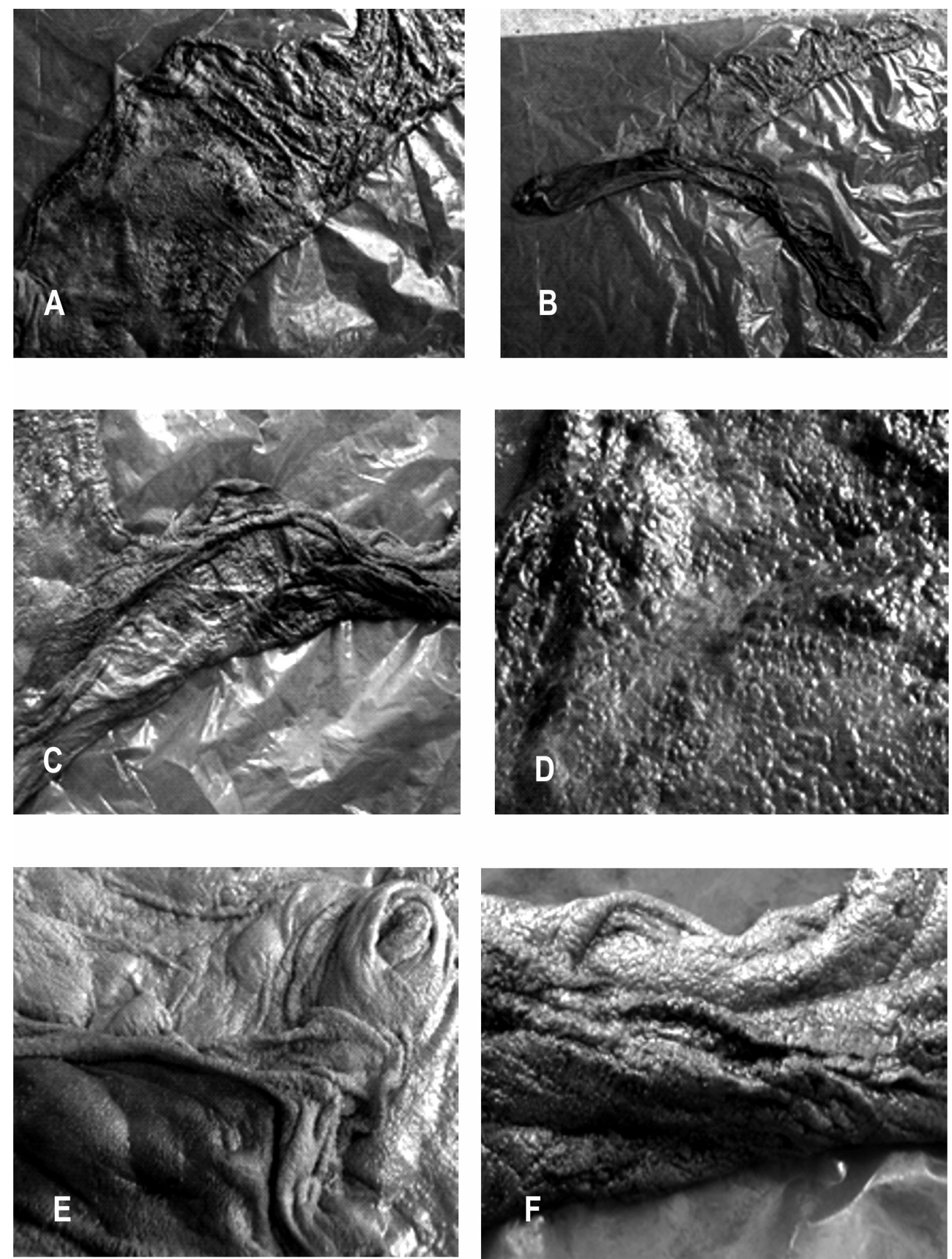

Figura 2. Tejido placentario. A) Placenta completa; B) Alantoamnios de aspecto edematoso y coloración rojiza generalizada; C) Alantocorion, superficie externa de color café con áreas de coloración oscura y aspecto rugoso; D) Zonas hemorrágicas con presencia de fibrina; E) Engrosamiento de la desembocadura del cordón umbilical con extensa área rojiza y formación de pliegues, presencia de congestión por el aumento del fibrinógeno ; F) Alantocorion en el interior extensas áreas grises con aparente desvitalización tisular delimitadas en algunas regiones por zonas de aspecto hemorrágico y alrededor zonas extensas de moderado enrojecimiento difuso. Fuente: elaboración propia. 
Tabla 2. hallazgos anatomopatológicos a la necropsia de un feto abortado proveniente de una yegua Silla Francesa en la ciudad de Bogotá.

\begin{tabular}{|c|c|}
\hline Órgano o zona examinada & Hallazgo \\
\hline Cavidad abdominal & Escaso líquido translúcido. \\
\hline Hígado & $\begin{array}{l}\text { Múltiples cambios de coloración entremezclados irregularmente } \\
\text { que le otorgan un aspecto moteado al órgano, algunas áreas pálidas } \\
\text { amarillentas, otras levemente enrojecidas y otras de color rojo } \\
\text { oscuro que se delimitaban bien del resto del parénquima. }\end{array}$ \\
\hline Estómago & $\begin{array}{l}\text { En la mucosa múltiples nodulaciones entre } 0.1- \\
0.3 \mathrm{~cm} \text { de coloración entre roja y amarilla. }\end{array}$ \\
\hline Intestino delgado & $\begin{array}{l}\text { Serosa con moderado enrojecimiento y algunos segmentos con } \\
\text { aspecto cianótico, en yeyuno resaltan los vasos de la serosa } \\
\text { que se encuentran moderadamente congestionados; en la luz } \\
\text { moderada cantidad de material semilíquido amarillento. }\end{array}$ \\
\hline Ciego y colon & $\begin{array}{l}\text { Serosa de coloración verdosa de manera generalizada, en la luz } \\
\text { abundante material verde oscuro de consistencia pastosa. }\end{array}$ \\
\hline Linfonodos mesentéricos & Moderadamente incrementados de tamaño, con enrojecimiento moderado. \\
\hline Bazo: & Leve esplenomegalia. \\
\hline Riñones: & Moderado enrojecimiento bilateral de la unión médulo-cortical. \\
\hline Pulmones & $\begin{array}{l}\text { Moderado cambio de coloración bilateral a cianótico oscuro; } \\
\text { impresiones costales severamente marcadas en ambos pulmones. }\end{array}$ \\
\hline Glándulas adrenales & Levemente incrementadas de tamaño. \\
\hline
\end{tabular}

\section{Hallazgos histopatológicos}

Los hallazgos histopatológicos más relevantes del feto se resumen en la tabla 3

Placenta (amnios-alantocorion): Entre las vellosidades moderada cantidad de material proteináceo, detritus celulares, eritrocitos extravasados, adheridos a la superficie celular moderada cantidad de cocobacilos, el tejido conectivo muestra severas hemorragias, moderada presencia de microtrombos.

\section{Discusión}

Los signos clínicos presentados por la paciente: lactancia prematura, inquietud, relinchos, dolor en la zona abdominal coinciden cuando una yegua está en proceso de aborto. En este caso en particular el cuadro hemático no arrojó ninguna indicación de proceso infeccioso y/o inflamatorio agudo (Hafez y Hafez, 2002; Córdoba, 2006). Las yeguas que están predispuestas a sufrir placentitis a menudo tienen inadecuada conformación perineal que predispone anatómica y funcionalmente la consolidación del proceso infeccioso ascendente que desencadena el cuadro inflamatorio de las membranas fetales.
Esta patología no tiene predilección de raza; la presentación clínica más común es un desarrollo prematuro de la ubre, con o sin secreción vulvar; el desarrollo precoz de la glándula mamaria asociado a gestación es frecuentemente encontrado cuando hay una anormalidad placentaria tal y como fue observado en la paciente del presente caso. Es probable que la descarga vulvar esté presente en las yeguas afectadas, pero puede ser producida en cantidades escasas que podría ser difícil de ver sin un examen clínico cuidadoso, además, pequeñas cantidades de descarga vulvar pueden ser fácilmente retiradas de la vulva por los movimientos periódicos de la cola. No obstante, en yeguas con riesgo de placentitis bacteriana se debe hacer seguimiento exhaustivo de la vulva, pelos de la cola y miembros posteriores en busca de pruebas de la descarga procedente del tracto reproductivo caudal; a este respecto, la identificación temprana de los signos clínicos de placentitis facilita el pronto inicio del tratamiento, con el fin de llevar a cabo la gestación a término (Macpherson y Bailey 2008; Curcio et al., 2017).

En yeguas con placentitis, el cuadro hemático puede evidenciar leucocitosis con neutrofilia. Este resultado paraclínico es variable porque la infección no suele ser de importancia sistémica, así mismo en casos avanzados puede existir una hiperfibrinogenemia, Lyle (2014). 
Tabla 3. Hallazgos histopatológicos a la necropsia de un feto abortado proveniente de una yegua Silla Francesa en la ciudad de Bogotá.

\begin{tabular}{|l|l|}
\hline Órgano o zona examinada & \multicolumn{1}{c|}{ Hallazgo } \\
\hline Cordón umbilical & $\begin{array}{l}\text { Las fibras musculares de la capa interna y externa están severamente } \\
\text { separadas por edema y algunas tienen el sarcoplasma fragmentado, } \\
\text { congestión de los vasos de la gelatina de Wharton, formación } \\
\text { de microtrombos y discretas áreas de hemorragias } \\
\text { Pleura con severo edema, congestión, los septos alveolares } \\
\text { moderadamente congestionados; en la luz de los alveolos } \\
\text { escasa cantidad de eritrocitos extravasados (hemorragias } \\
\text { Lígado cordones hepáticos están desorganizados, los hepatocitos } \\
\text { tienen el citoplasma vacuolar, las venas centrales exhiben } \\
\text { material granular eosinofilico que corresponde a plasma. } \\
\text { Presencia de cocobacilos Gram negativos adheridos a la superficie de las } \\
\text { células de las vellosidades corioalantóicas y entremezclados con el material } \\
\text { proteináceo, aparentemente algunos se ubican intracelularmente. }\end{array}$ \\
\hline $\begin{array}{l}\text { Diagnóstico Histopatológico: Aborto infeccioso bacteriano asociado a placentitis } \\
\text { ascendente (Posibles enterobacterias E.coli, Salmonella sp. entre otras). }\end{array}$ \\
\hline
\end{tabular}

La placentitis asociada con aborto temprano tiende a ser aguda y el feto muere por bacteriemia y los abortos hacia la etapa final de la gestación tienden a estar asociados con placentitis crónica y grave reacción tisular, que da lugar a una insuficiencia uteroplacentaria, Reed et al., 2005). Para el caso de la paciente del presente caso, el hemograma no reportó anormalidades lo cual sugiere que el proceso fue agudo y no alcanzó a presentar respuesta por parte del organismo.

El aborto en yeguas tiene una incidencia entre el 5\% y el $15 \%$, más que en otras especies (Hafez y Hafez, 2002; Córdoba, 2006). Las pérdidas de preñez de más de cinco meses siguen siendo un problema serio para los propietarios de caballos, afectando los parámetros de la eficiencia reproductiva, Roberts, (1986). Por otra parte, las pérdidas de gestaciones avanzadas se deben entre otras causas a: a) Entrada de bacterias (Streptococcus zooepidemicus, E. coli, Pseudomonas aeruginosa, Klebsiella pneumoniae var genitalium, Staphylococcus aureus, Streptococcus equisimilis, Leptospira spp., Salmonella abortus equi) en el útero provocando placentitis extensa. Las bacterias también pueden penetrar al útero por corriente sanguínea de la madre produciendo septicemia o bacteremia con muerte fetal y aborto, (b) por virus, como el herpes virus equino 1 (EHV1) o virus de la rinoneumonitis equina, c) gestaciones gemelares; la yegua, a diferencia de otras especies, no es lo suficientemente capaz de mantener dos fetos durante toda la gestación, ya sea por competencia de los nutrientes o por deficien- cia de las membranas fetales, presentando insuficiencia placentaria y con ello la muerte de uno o ambos fetos (Hafez y Hafez, 2002; Córdoba, 2006), d) torsión del cordón umbilical "sobre sí mismo" o en el cuerpo del feto dificultándole la circulación, e) las anomalías fetales como la hidrocefalia, f) exceso de fluido fetal que puede provocar desprendimiento de la placenta y en consecuencia aborto, y g) por acción iatrogénica al administrar fármacos que interrumpen la gestación, Córdoba (2006). En este caso, las evidencias encontradas a nivel histopatológico sugieren que la causa mas probable de la placentitis ascendente de origen bacteriano y más específicamente causada por enterobacterias de los géneros E. coli y Salmonella spp.

Por medio de la ultrasonografía transabdominal los valores normales para el espesor conjunto de útero y placenta (ECUP) o también denominado espesamiento útero-placentario combinado (CUPT) han sido determinados mediante mediciones del grosor del útero y placenta, extremos caudales, craneales, en la mitad de los cuernos uterinos, arteria uterina y líquido alantoideo sin incluir el borde dorsal (Troedsson et al., 1997; Troedsson y Zent, 2004; Troedsson y Sage, 2001). Los valores ultrasonográficos tomados como guía en preñeces normales deben tener un ECUP de 7,1 +/- 1,6 mm como mínimo y 11,5 +/- 2,4 mm como máximo.

En estudios posteriores con ECUP aumentado, frecuentemente los potros nacen anormales; y con un ECUP $>17,5 \mathrm{~mm}$ es representativo de placentitis. Pero estas medidas estandarizadas tendrán una variante, y 
eso será el tiempo de gestación. Es así como, un ECUP <8 mm será para intervalos entre los 271 a 300 días de gestación (10 meses), <10 mm para 301 a 330 días de gestación (11 meses), y <12 mm para gestaciones mayores a 330 días (12 meses). La mayoría de las yeguas tienen un ECUP de $<12 \mathrm{~mm}$ al momento del parto. Con una medida de $>15 \mathrm{~mm}$ en yeguas puras y >12mm en yeguas ponny después de los 310 días de gestación se puede considerar que hay una alteración en la función placentaria (LeBlanc et al., 2004; Bucca et al., 2005); es así que el engrosamiento de la placenta y la separación parcial del alantocorion del endometrio, puede observarse en placentitis originada por infección hematógena, LeBlanc et al., (2004); aunque la ultrasonografía transabdominal suministra una muy buena imagen del feto, la mayor parte del útero, placenta y la porción caudal del alantocorion no pueden observarse, haciendo difícil el diagnóstico en las placentitis ascendentes en estadios iniciales Troedsson y Sage, (2001). Para la paciente del presente caso, el valor estaba en $18 \mathrm{~mm}$ lo cual fue un indicador claro de placentitis.

A través de la ultrasonografía transrectal, se ha encontrado espesor anormal y separación parcial del alantocorion con el endometrio en yeguas que presentaban signos clínicos de placentitis ascendente (Troedsson et al., 1997; Troedsson y Zent, 2004; Stauffert et al., 2011).

Un mecanismo para diagnosticar condiciones de estrés fetal o placentitis es la medición plasmática de progesterona (P4) (Wynn et al., 2016; LeBlanc M et al., 2004; Rossdale et al., 1991). En una yegua normal, las concentraciones plasmáticas de P4 se encuentran entre 3-6 ng/mL desde el día 110 hasta el décimo mes de gestación, Terblanche y Maree (1981) (ver tabla 4); por otro lado, los niveles de progestágenos en plasma aumentan en los últimos 15-21 días antes del parto, estos mismos niveles disminuyen en las últimas 48 horas antes de parir (LeBlanc M et al., 2004; Small, 2000). Prematuramente el aumento de los niveles plasmáticos de P4 podría ser un indicador de placentitis crónica o estrés fetal (Bucca et al., 2005; LeBlanc, 2004; Rossdale, 1991; Stawicki et al., 2002; Ousey et al., 2006). Para el caso específico de la paciente, no se contaba con el kit necesario para hacer la medición plasmática de la P4 pero los hallazgos del ECUP sugieren que de haberse tomado, hubiesen evidenciado resultados por encima de $6 \mathrm{ng} / \mathrm{mL}$.

Otra medida que puede ser tenida en cuenta en eventos futuros como indicador de bienestar fetal es la de estrógeno total plasmático la cual debe ser medida entre los 150 y 280 días de gestación cuyos resultados
Tabla 4. Los niveles plasmáticos de progesterona durante la preñez normal de la yegua, adaptado de Terbanche y Mare, 1981 (25).

\begin{tabular}{|c|c|}
\hline $\begin{array}{c}\text { Día de } \\
\text { gestación }\end{array}$ & $\begin{array}{c}\text { Nivel de progesterona } \\
\text { plasmática }(\mathbf{n g} / \mathbf{m L})\end{array}$ \\
\hline $21-30$ & $5-9$ \\
\hline $30-60$ & $14-10$ \\
\hline $60-110$ & $7-10$ \\
\hline $110-300$ & $3-6$ \\
\hline
\end{tabular}

son $>1000 \mathrm{ng} / \mathrm{mL}$ para un feto en normalidad, $<1000$ $\mathrm{ng} / \mathrm{mL}$ indicador de estrés fetal y $<500 \mathrm{ng} / \mathrm{mL}$ es indicador de alteraciones gestacionales graves (LeBlanc et al., 2004; Curcio et al., 2017).

Por otro lado, las concentraciones de la relaxina podrían ser potencialmente útiles en el diagnóstico de insuficiencia placentaria ya que se produce principalmente en la placenta Ousey et al., (1995). Sin embargo, la medición de la concentración de la relaxina en yeguas no es rutinariamente analizada en Colombia.

Los antibióticos de amplio espectro que han sido recomendados para placentitis bacteriana son Trimetoprim- Sulfadiazina (de 15 a $30 \mathrm{mg} / \mathrm{Kg}$, oral, cada 12 horas), Penicilina procaínica $(30000 \mathrm{UI} / \mathrm{Kg}$, IM, cada 24 horas) y Ceftiofur ( $1-5 \mathrm{mg} / \mathrm{Kg}$, IM o IV, cada 12 horas) (Rose-Hodgson, 1995; Rebello et al., 2006). Sin embargo, se ha estudiado que la penetración de antibióticos a través de la placenta es muy escasa, por éste motivo se realizó un estudio que medía cual era la llegada de algunos antibióticos comúnmente utilizados (Penicilina potásica y Gentamicina, TrimetoprimSulfadiazina y Penicilina potásica) a la placenta, fluidos placentarios y suero fetal; estudio que monitoreo la concentración tisular y líquidos en mención de estos antibióticos diariamente; la Penicilina fue detectada en suero materno y líquido alantoideo, pero no se detectó en líquido amniótico y suero fetal; por otro lado, la Gentamicina se encontró en líquidos placentarios y suero fetal pero por debajo de la dosis mínima efectiva; es así, que se determinó que la Penicilina y Gentamicina tenían pasaje a través de las membranas fetales, pero la concentración del medicamento hallado en el feto no era lo suficientemente alto como para hacer frente a la infección. Sin embargo, con TrimetoprimSulfadiazina la concentración detectada en líquidos fetales fue suficiente para actuar ante el agente bacteriano, esta combinación farmacológica posibilita prolongar la gestación en casos de yeguas con placentitis LeBlanc et al., (2004); es así, que el tratamiento 
combinado con antiinflamatorios no esteroidales es necesario para combatir la infección bacteriana y a su vez suprimir la respuesta inflamatoria subsecuente (Reed et al., 2005; Christiansen et al., 2010; Bailey et al., 2010; LeBlanc et al., 2012). En el presente caso, la terapia con penicilina $\mathrm{G}$ sódica, penicilina $\mathrm{G}$ potásica y estreptomicina por un lapso de diez días fue suficiente para tratar la infección uterina sin dejar secuelas posteriores.

La efectividad de la terapia antiinflamatoria en yeguas preñadas no está bien documentada, se sabe que hay una elevación en las concentraciones de prostaglandina $E_{2}$ y prostaglandina $F_{2}$ y de citocinas proinflamatorias como IL-6 e IL-8, sobre muestras de fluido alantoideo hasta 48 horas después del aborto o parto prematuro inducidos experimentalmente LeBlanc et al., (2004) o cuadros clínicos de placentitis (Bailey et al., 2010; LeBlanc et al., 2012), sumado a una escasa penetración de agentes antiinflamatorios en la placenta de yeguas sanas y con placentitis (LeBlanc et al., 2004; Bailey et al., 2010). Aun así se recomienda la administración de pentoxifilina, un derivado xantínico $(8,8 \mathrm{mg} / \mathrm{kg}$, VO cada 24 horas), fármaco que disminuye la viscosidad sanguínea al aumentar la flexibilidad de los glóbulos rojos; y tiene capacidad para modular el proceso inflamatorio (Bailey et al., 2010; Colón, 2009). Otros estudios promueven la utilización de Ácido Acetil-salicílico (50 mg/kg, vía oral, cada 12 horas) como inmunomodulador y anti-inflamatorio; su uso se ha propuesto alternativamente a la utilización de pentoxifilina, porque ésta última no aumentaría el flujo uterino de la arteria uterina en yeguas viejas con endometrosis y preñadas, LeBlanc (2012).

Aún cuando la $\mathrm{PGF}_{2 \alpha}$ induce secuestro esteroidogénico alterando la producción de progesterona, existe poca evidencia científica de la necesidad de suplementación con progestágenos cuando se sospecha de inflamación útero- placentario (Reed et al., 2005; LeBlanc et al., 2012), donde Altrenogest $(0,088 \mathrm{mg} / \mathrm{kg}$, vía oral, cada 24 horas) a doble dosis presentó los mejores resultados clínicos (Small, 2000; Bailey et al., 2010). La terapia tocolítica previene las contracciones uterinas y en el trabajo de parto prematuro, los tocolíticos prolongan la preñez por alrededor de 48 horas; durante ese tiempo, se puede administrar glucocorticoides a la madre para favorecer la maduración fetal, es así que el Clembuterol, un agente $\beta$-simpaticomimético es de los más utilizados para inducir el efecto relajante del miometrio en la yegua, los efectos en su administración son a nivel del tono uterino, latido cardíaco materno y fetal, su administración endovenosa demostró un decremento en el tono uterino, comenzando los efectos luego de los 3 minutos y persistiendo hasta los 120 minutos post- administración LeBlanc (2004); además de los efectos antiinflamatorios al activar los receptores $\beta_{2}$-adrenérgicos en la membrana celular de los leucocitos, lo cual conduce a un aumento de la molécula de señalización intracelular antiinflamatoria: adenosina monofosfato cíclico (AMPc) Van Miert (2002), por esta razones el Clembuterol también se asocia a las terapias de control de endotoxemia en equinos Cudmore (2013). Otros reportes, Saavedra (2009), indican que el flunixin meglumine se usa para suprimir la formación de mediadores de inflamación o minimizar su efecto pues se suprimen citokinas y prostaglandinas del líquido amniótico suprimiendo el cuadro inflamatorio el cual fue usado en este caso con buen resultado.

En la tabla 3 (LeBlanc, 2010) resume los antibióticos, antiinflamatorios y tocolíticos que fueron usados en yeguas con placentitis ascendente hasta la fecha.

El objetivo del lavado uterino se explica desde tres finalidades: I. físicamente elimina las bacterias y restos celulares, reduciendo potencialmente el riesgo de metritis secundaria, septicemia, y laminitis; II. estimula la contractilidad uterina, mejorando la involución uterina; III. es particularmente útil en casos en los que una pequeña porción de las membranas fetales sea retenida en el útero, permitiendo su remoción física y expulsión, Lopate (2003). El lavado uterino se realiza de una a tres veces al día, utilizando gran volumen (1020 L) de solución de lactato de Ringer o agua enriquecida con 8,5 g de cloruro de sodio por litro, Brinsko (2001). El uso de Plasmalyte solución debe evitarse, ya que contiene considerables cantidades de gluconato, el cual puede ser sustrato de crecimiento para E. coli, un contaminante común en el útero después del parto de la yegua (Lopate et al., 2003; LeBlanc, 2008; Wang y Dykhuizen, 2001). El lavado se realiza normalmente utilizando una sonda nasogástrica $(14-17 \mathrm{~mm}$ de diámetro), algunos especialistas recomiendan la adición de povidone iodine $(1: 1000 \mathrm{v} / \mathrm{v} ; 0,05 \%-0,1 \%)$ Canisso et al., (2013), pero la precaución extrema se debe ejercer porque este antiséptico, cuando se utiliza en altas concentraciones, puede causar irritación endometrial e incluso necrosis, Lopate et al., (2003). Por otra parte, algunos clínicos sospechan que el lavado uterino en yeguas con retención de membranas fetales mejorará la absorción de endotoxina y la translocación bacteriana desde del lumen del útero a la corriente sanguínea (Canisso et al., 2013; Rapacz et al., 2012). El lavado uterino realizado a la paciente del presente caso fue realizado con lactato de ringer atemperado con solución $0,1 \%$ de yodo mostrando excelentes resultados en un seguimiento ecográfico posterior a la presentación del aborto con lo cual se sugiere como 
Tabla 5. Tratamiento farmacológico de placentitis en yeguas

\begin{tabular}{|c|c|c|}
\hline Agente terapéutico & Dosis orientativa & Mecanismo de acción farmacológico \\
\hline Trimetoprim-Sulfa & $15-30 \mathrm{mg} / \mathrm{kg}, \mathrm{PO}, \mathrm{q} 12 \mathrm{~h}$ & Antimicrobiano \\
\hline Penicillina G potásica & $22000 \mathrm{IU} / \mathrm{kg}$, IV, q $6 \mathrm{~h}$ & Antimicrobiano \\
\hline Gentamicina & $6.6 \mathrm{mg} / \mathrm{kg}$, IV, q $24 \mathrm{~h}$ & Antimicrobiano \\
\hline Ceftiofur & $20 \mathrm{mg} / \mathrm{kg}$, IV or IM, q $12 \mathrm{~h}$ & Antimicrobiano \\
\hline Altrenogest & $0.088 \mathrm{mg} / \mathrm{kg}, \mathrm{PO}, \mathrm{q} 24 \mathrm{~h}$ & $\begin{array}{l}\text { Tocolítico; previene aborto } \\
\text { mediado por prostaglandina }\end{array}$ \\
\hline Isoxsuprina & $0.4-0.6 \mathrm{mg} / \mathrm{kg}, \mathrm{PO}, \mathrm{q} 24 \mathrm{~h}$ & Tocolítico \\
\hline Clembuterol & $0.8 \mu \mathrm{g} / \mathrm{kg}, \mathrm{PO} / \mathrm{IV}, \mathrm{q} 12 \mathrm{~h}$ & Tocolítico \\
\hline Flunixin meglumina & $1.1 \mathrm{mg} / \mathrm{kg}, \mathrm{PO} / \mathrm{IV}, \mathrm{q} 12$ or $24 \mathrm{~h}$ & $\begin{array}{l}\text { Antiinflamatorio, previene aborto } \\
\text { mediado por prostaglandina }\end{array}$ \\
\hline Fenilbutazona & $2.2 \mathrm{mg} / \mathrm{kg}, \mathrm{PO}, \mathrm{q} 12 \mathrm{~h}$ or $24 \mathrm{~h}$ & Antiinflamatorio \\
\hline Pentoxifilina & $8.5 \mathrm{mg} / \mathrm{kg}, \mathrm{PO}, \mathrm{q} 12 \mathrm{~h}$ & $\begin{array}{l}\text { Bloquea el factor de necrosis tumoral e IL-6 } \\
\text { inducidos por endotoxina, actividad anticitotóxica }\end{array}$ \\
\hline Ácido Acetilsalicilico & $50 \mathrm{mg} / \mathrm{kg}, \mathrm{PO}, \mathrm{q} 12 \mathrm{~h}$ & Mejora el flujo sanguíneo \\
\hline Dexametazona & $\begin{array}{l}40,35,25 \mathrm{mg} \text {, q } 24 \mathrm{~h} \text {, IV (give over } \\
6 \text { days; decreasing dose every } 48 \text { h) }\end{array}$ & $\begin{array}{l}\text { Antiinflamatorio; estimulante } \\
\text { de la maduración fetal }\end{array}$ \\
\hline
\end{tabular}

Fuente: LeBlanc, M., 2010 (40).

parte del protocolo de manejo posterior al episodio clínico.

Para prevenir las pérdidas gestacionales avanzadas, se debe establecer la valoración ultrasonográfica de la placenta y del feto. En la placenta se debe tener en cuenta los valores del espesor de la unidad úteroplacentaria (ECUP), del volumen y descripción de la ecogenicidad de los líquidos placentarios y en el feto se evalúa el diámetro de la aorta, la frecuencia cardiaca, la presentación fetal, desde el cuarto al onceavo mes de gestación, con el fin de determinar los rangos o parámetros, en estas etapas y en el futuro predecir la viabilidad fetal y aplicar los correctivos preventivos o terapéuticos pertinentes (Vega, 2013; Renaudin et al., 1997; Renaudin et al., 1999; Campos et al., 2017).

\section{Conclusiones}

Este reporte de caso permitió documentar y socializar la ocurrencia de placentitis causada por bacterias (posibles enterobacterias E.coli, Salmonella spp.) en la yegua.

Así mismo debe considerarse la ultrasonografía como herramienta de rutina durante la preñez avanzada o tardía para determinar cualquier cambio anatomofisiológico del feto y/o sus membranas, pero para ello es indispensable confrontar los valores mínimos y máximos del volumen de los líquidos fetales, así mismo los del espesor conjunto de la unión del útero y la placenta (ECUP) ya que son diferentes en cada tipo de raza.

En reproducción equina se debe evaluar la estructura placentaria y las condiciones fetales en las gestaciones tardías con el fin de verificar el estado de salud del feto, sobre todo en los casos de yeguas con sospecha de flujo vaginal, lactancia prematura, excesiva distensión de la cavidad abdominal y partos distócicos anteriores, Benirschke (2001).

El tratamiento con penicilina G Sódica y G Procaínica en asocio con estreptomicina como antibiótico y un aine como Flunixin meglumine es de utilidad para contrarrestar los efectos secundarios de la placentitis en la yegua, así como también se hace necesaria la aplicación de oxitocina y realización un lavado uterino que ayude en la eliminación de cualquier residuo dentro del útero.

Hasta donde se conoce no existen en Colombia reportes de placentitis en yeguas causada por bacterias, por lo cual este reporte se trata de uno de los primeros realizados en este campo de la clínica reproductiva de esta especie de alta importancia económica nacional, 
es muy probable que la casuística de placentitis bacteriana causa de aborto en yeguas en el país sea mayor.

\section{Referencias}

Hong C, Donahue R, Giles Jr M, Petrites-Murphy M, Poonacha K, Roberts A, et al. Etiology and pathology of equine placentitis. J Vet Diagn Inv. 1993;5:56-63.

Pycock J. 2009. Complicaciones de la gestación avanzada en la yegua. Congreso Argentino de Reproducción Equina, 18-21 de marzo de 37-42.

Munroe G, Weese J. 2011. Equine Clinical Medicine, Surgery, and reproduction. Barcelona: Manson. 272.

Williams M, Donahue J, Bolin D, Giles R, Harrison L, Hong C. 2004. Equine placental pathology: Kentucky perspective. Proc Workshop Equine Placenta. Pp. 88-92.

Canisso I, Ball B, Erol E, Squires E, Troedsson M. Comprehensive review on equine placentitis. Proc Am Assoc Equine Pract. 2015;61:490-509.

Troedsson M, Renaudin C, Zent W, Steiner J. Transrectal ultrasonography of the placenta in normal mares and mares with pending abortion: a field study. Proc Am Assoc Equine Pract. 1997;43:256-258.

Reed S, Baylv W, Sellon D. 2005. Medicina Interna Equina. Parte II. Editorial Intermédica. Segunda Edición. 1204-1205.

Troedsson M, Zent W. Clinical ultrasonographic evaluation of the equine placenta as a method to successfully identify and treat mares with placentitis. Proc Workshop Equine Placenta. 2004;1:66-67.

Wynn M, Fedorka C, Ball B, Cray C, Canisso I, Curry Jr T, et al. A prospective case-control study of biomarkers for fetoplacental well-being in the mares. Proc Am Assoc Equine Pract. 2016;62:351.

Robinson E. 1992. Terapéutica actual en medicina equina. Buenos Aires: Intermédica. Pp. 561-562.

LeBlanc M, Macpherson M, Sheerin P. 2004. Ascending placentitis: What we know about pathophysiology, diagnosis, and treatment. In: Proceedings of the 50th Annual Convention of the American Association of Equine Practitioners. Denver, Colorado. Ithaca: International Veterinary Information Service.

Carleton C. 2011. Equine theriogenology. Michigan:Wiley-Blackwell. Pp.426-432.

Lyle S. Immunology of infective preterm delivery in the mare. Equine Vet J 2014;46:661-668.

Hafez E, Hafez B. 2002. Caballos. Capítulo 14. Reproducción e inseminación artificial en animales. McGraw-Hill Interamericana. $7^{\text {a }}$ edición. México. 199-216.

Córdoba A. 2006. Factores relacionados con el aborto en yeguas. Revista Electrónica de Veterinaria REDVET. http://www.veterinaria.org/revistas/ redvet/n010106.html
Macpherson M, Bailey C. A clinical approach to managing the mare with placentitis. Theriogenology. 2008;70:435-440.

Curcio B, Canisso I, Pazinato F, Borba L. et al. Estradiol cypionate aided treatment for experimentally induced ascending placentitis in mares. Theriogenology. 2017;102:98-107.

Roberts S. 1986. Veterinary Obstetrics and Genital Diseases. Theriogenology. In: Roberts S.J. ed., North Pomfret, Vt, $3^{\text {rd }}$ ed. 162. Pp. 38-50.

Benirschke K. Fetal consequences of amniotic fluid meconium. Contemporary Obstetrics \& Gynecology. 2001;46:76-83.

Troedsson M, Sage A. 2001. Fetal placental evaluation in the mare. In: Recent Advances in Equine Reproduction. Edited by B.A.Ball. Ithaca: International Veterinary Information Service.

Bucca S, Fogarty U, Collins A, Small V. Assessment of feto-placental well-being in the mare from mid-gestation to term: transrectal and transabdominal ultrasonographic features. Theriogenology. 2005; 64:542-557.

Stauffert R, Lins L, Frey J, Nogueira C. 2011. Estudio de la unión útero-placentaria en yeguas para el monitoreo de la gestación y su relación con el potrillo problema. Jornadas de actualización, Reproducción Equina II. Río Cuarto. 601-604.

LeBlanc M. 2004. Ascending placentitis in the mare: what we learned from an experimental model. In: Procceding of the 10 Congresso Nazionala Multisala SIVE Perugia.Ithaca: International Veterinary Information Service.

Canisso I, Rodriguez J, Sanz M, Coutinho da Silva M. A clinical approach to the diagnosis and treatment of retained fetal membranes with an emphasis placed on the critically III mare. J Equine Vet Sci. 2013;33:570-579.

Terblanche H, Maree L. Plasma progesterone levels in the mare during the oestrous cycle and pregnancy. Js Afr Vet Assoc. 1981;52:181-185.

Small V. 2000. Transabdominal and transrectal ultrasound scaning of the pregnant mare from five months to term. Masters in Veterinay medicine thesis University College Dublin,Dublin,Ireland.

Rossdale P, Ousey J, Cottrill C, Chavatte P, Allen W, McGlanddery A. Effects of placental pathology on maternal plasma progestagen and mammary secretion calcium concentrations and on neonatal adrenocortical function in the horse. J Reprod Fertil Suppl. 1991;44:579-590.

Stawicki R, Ruebel H, Hansen P, Sheerin B, O'Donnell L, Lester G, Paccamonti $\mathrm{D}$, LeBlanck $M$. Endocrinological findings in an experimental model of ascending placentitis in the mare. Theriogenology. 2002;58:849-852.

Ousey J, Kolling M, Allen W. The effecs of maternal dexamethasone treatment on gestation length and foal maturation in Thoroughbred mares. Anim Reprod Sci. 2006;94:436-438.

Ousey J, Houghton E, Grainger L, Rossdale P, Fowden A. Progestagen profiles during the last trimester of gestation in thoroughbred mares with normal or compromised pregnancies. Theriogenology. 2005;63:1844-1856. 
Rose-Hodgson. 1995. Manual clínico de equinos. Editorial interamericana S.A.

Rebello S, Macpherson M, Murchie T, LeBlanc M, Vickroy T. Placental transfer of trimethoprim sulfamethoxazole and pentoxifylline in pony mares. Anim Reprod Sci. 2006;94:432-433.

Christiansen D, Moultona K, Hopper R, Walters F, Cooleya A, LeBlanc M. et al. Evidenced-based medicine approach to develop efficacious therapies for late-gestation mares presenting with uterine infections using an experimentally-induced placentitis model. Anim Reprod Sci. 2010;121:S345-S346.

Bailey C, Macpherson M, Pozor M, Troedsson M, Benson S, Giguere $S$, et al. Treatment efficacy of trimethoprim sulphametoxazole, pentoxifilyne and altrenogest in experimentally induced equine placentitis. Theriogenology. 2010;74:402-412.

LeBlanc M, Giguere S, Lester G, Bauer K, Paccamonti L. Relationship between infection, inflammation and premature parturition in mares with experimentally induced placentitis. Equine Vet J Suppl. 2012;41:8-14.

Colón J. 2009. Apariencia en la ecografía transrectal del engrosamiento combinado útero-placentario anormal en el último período de la gestación La especie Equina $\mathrm{N}^{\circ} 28$. 20-32.

Van Miert A. Present concepts on the inflammatory modulators with special reference to cytokines. Vet Res Commun. 2002;26:111126.

Cudmore L, Muurlink T, Whittem T, Bailey S. Effects of oral clenbuterol on the clinical and inflammatory response to endotoxaemia in the horse. Res Vet Sci. 2013;94:682-686.

Saavedra PD. 2009. Estudio Ecográfico del Grosor de la Unión Uteroplacentaria en Yeguas Fina Sangre de Carrera Menores y Mayores de 14 Años, Clínicamente Sanas, a Partir de los 240 Días de Gestación. Tesis (Título Médico Veterinario). Santiago, Chile, Universidad Mayor. 50-62 p

LeBlanc M. Ascending placentitis in the mare: an update. Reprod Dom Anim. 2010;45:28-34.
Lopate C, Leblanc M, Pascoe R, Knottenbelt D. 2003. Parturition. In: Knottenbelt, D; LeBlanc, M; Lopate, C; Pascoe, R; editors. Equine stud farm medicine and surgery. Edinburgh: Saunders. Pp. 269-324.

Brinsko S. How to perform uterine lavage: Indications and practical techniques. Proc Am Assoc Equine Pract. 2001;47:407-411.

LeBlanc M. Common peripartum problems in the mare. J Equine Vet Sci. 2008;28:709-715.

Wang I, Dykhuizen D. Variation of enzyme activities at a branched pathway involved in the utilization of gluconate in Escherichia coli. Evolution. 2001;55:897-908.

Rapacz A, Pazdizior K, Ras A, Rotkiewicz T, Janowski T. Retained fetal membrane in heavy draft mares associated with histological abnormalities. J Equine Vet Sci. 2012;32:38-44.

Vega F. Medidas ultrasonográficas del espesor conjunto de la unión útero-placentaria en yeguas criollas colombianas. Acta Agronómica. 2013;62(2):148-154

Renaudin C, Troedsson M, Gillis C, King V, Bodena A. Ultrasonographic evaluation of the equine placenta by transrectal and transabdominal approach in the normal pregnant mare. Theriogenology. 1997;47:559-573.

Renaudin C, Liu I, Troedsson M. Transrectal ultrasonographic diagnosis of ascending placentitis in the mare: a report of two cases. Equine Vet Educ. 1999;11(2):69-74.

Renaudin C, Liu I, Troedsson M. Transrectal ultrasonographic diagnosis of ascending placentitis in the mare: a report of two cases. Equine Vet Education. 1999;11:69-74.

Campos I, de Souza G, Pinna A, Ferreira A. Transrectal ultrasonography for measuring of combined uteroplacental thickness in pregnant Mangalarga Marchador mares. Theriogenology. 2017;96:142-144 